\title{
Métodos de cotação e negociação na cadeia de suprimentos de autopeças brasileira e os custos de transação
}

\section{Pricing and negotiation methods used in brazilian auto parts supply chain and their transaction costs}

\author{
Edélcio Genaro'1 \\ Wilson de Castro Hilsdorf ${ }^{1}$ \\ Mauro Sampaio ${ }^{1}$
}

\begin{abstract}
Resumo: O presente trabalho tem por objetivo principal identificar quais são os métodos de cotação e negociação de preços predominantes na cadeia de suprimentos de autopeças brasileira. Ainda dentro do escopo do trabalho, buscou-se determinar como as características dos métodos de cotação e negociação de preços utilizados na cadeia de suprimentos de autopeças brasileira afetam os custos de transação. O interesse recaiu sobre a cadeia de suprimentos de autopeças do Brasil devido à sua complexidade, atualização tecnológica e crescimento acentuado nos últimos anos. Para alcançar os objetivos foi executada pesquisa tipo survey, com questionário enviado aos gestores da área de supply chain das 100 maiores empresas fabricantes de autopeças. Das respostas obtidas concluiu-se que as maiores empresas da cadeia de suprimentos de autopeças em termos de faturamento, com capital multinacional, empregam uma gama mais variada e estruturada de métodos de cotação e negociação de preços para aquisição de materiais diretos. Por outro lado as empresas de capital nacional empregam majoritariamente métodos mais simples de cotação e negociação de preço. O trabalho apresenta também, com base nas características principais dos métodos de cotação e negociação identificados, a percepção dos gestores de supply chain das empresas pesquisadas acerca da influência dessas características nos custos de transação.
\end{abstract}

Palavras-chave: Cadeia de suprimentos. Cadeia automotiva. Métodos de negociação. Custos de transação.

\begin{abstract}
This paper aims to identify the main methods of pricing and negotiation in the Brazilian auto parts supply chain and to determine how the characteristics of these methods affect transaction costs. The Brazilian auto parts supply chain was studied due to its complexity, technological upgrading, and growth in the recent years. To achieve these objectives, a survey was carried out and a questionnaire was sent to the supply chain managers of the 100 largest auto parts manufacturers. Based on the responses obtained, it was concluded that the largest multinational companies in the auto parts supply chain in terms of revenue use a wider range and more structured pricing and negotiation methods for the purchase of direct materials. On the other hand, domestic companies use mainly the simpler pricing and negotiation methods. The present study also presents, based on the characteristics of the major methods identified, the supply chain managers view about the influence of these characteristics on transaction costs.
\end{abstract}

Keywords: Supply chain. Automotive supply chain. Negotiation methods. Transaction Costs.

\section{Introdução}

A evolução no gerenciamento do fluxo de materiais nas últimas décadas do século XX tem colaborado com o desenvolvimento de maior integração entre os agentes. Processos e estratégias mais amplas começaram a ser implementados e as empresas perceberam a necessidade de gerenciar atividades externas à sua operação que influenciam diretamente $\mathrm{o}$ desempenho de todo o sistema. Da observação dessas práticas surgiram os primeiros estudos acadêmicos sobre esse novo sistema integrado, que foi chamado de Gestão da Cadeia de Suprimento, segundo
Coyle, Bardi e Langley Junior (2003). Com isso, verificou-se o crescimento do interesse pelos vários tipos de alianças ou parcerias estratégicas entre as empresas. Segundo Pires (2004), as empresas deveriam abandonar a forma tradicional de relacionamento em que ocorre uma simples relação oportunista de transação (compra/venda) sem que haja qualquer oportunidade colaborativa, passando a relacionamentos mais estáveis, duradouros e cooperativos. Para que a relação entre os integrantes da cadeia de suprimentos

\footnotetext{
Centro Universitário, Fundação de Educação Inaciana "Pe. Sabóia de Medeiros" - FEI, CEP 09850-901, São Bernardo do

Campo, SP, Brasil, e-mail: genaro.edelcio@gmail.com; wicastro@fei.edu.br; msampaio@ fei.edu.br
} 
seja de fato estável e duradoura, é importante o tipo de negociação que vai definir as bases da transação.

Segundo Zartman (2007), negociações ocorrem como modo de tomada de decisões quando não existem regras para reger a decisão nem a autoridade ou preço determinado para a troca de bens ou serviços. De acordo com Lempereur e Sebenius (2007), negociar é o ato de obter melhores resultados, que deverão ser consequência de um trade-off, ou seja, maximizar o lucro advindo da transação em curso ou diminuir o risco, o que poderá permitir, se aplicado na cadeia de suprimentos, a ocorrência de negócios e relações mais justas e de longo prazo, diminuindo os custos dessa transação.

Este trabalho teve como objetivo identificar os métodos de cotação e negociação mais utilizados na cadeia de suprimentos de autopeças brasileira. Nesse sentido, foi conduzida uma pesquisa tipo survey junto aos 100 maiores fornecedores de autopeças do Brasil (categorias sistemistas e tier 1), segundo a classificação do Sindicato Nacional da Indústria de Componentes para Veículos Automotores (Sindipeças) (2009-2010). Procurou-se também obter subsídios para identificar de que forma as características dos métodos de cotação e negociação de preços utilizados na cadeia de suprimentos de autopeças brasileira afetam os custos de transação. Em resumo, este trabalho procurou responder às seguintes questões de pesquisa:

- Quais métodos de cotação e negociação de preços predominam na cadeia de suprimentos de autopeças brasileira?

- De que forma as características dos métodos de cotação e negociação de preços utilizados na cadeia de suprimentos de autopeças brasileira afetam os custos de transação?

Na próxima seção é apresentado o referencial teórico utilizado para fundamentar a pesquisa, tratando da teoria da negociação, dos custos de transação e dos métodos de cotação e negociação comumente utilizados no setor de autopeças. Na sequência descreve-se brevemente a metodologia utilizada para o levantamento de dados e os resultados obtidos. A seguir esses resultados são discutidos, sendo apresentadas as conclusões.

\section{Referencial teórico}

\subsection{A teoria da negociação}

Levando-se em conta a afirmativa de Zartman (2007) de que negociações ocorrem como forma de tomada de decisões quando não existem regras para reger a decisão nem autoridade ou preço determinado para a troca de bens ou serviços, para que essas ocorram, as partes deverão estar com autonomia e independência, equiparadas e em mútuo acordo quanto aos termos da troca ou do compartilhamento dos diferentes ativos em transação. Nesse caso, o preço não é determinado pelo livre jogo da oferta e da demanda, como numa economia de mercado, mas essencialmente pelas diferentes dimensões constitutivas da demanda, incluindo os objetivos do poder, os interesses de cada uma das partes e o valor das soluções alternativas. Assim, não é simplesmente o valor fixado nem a disponibilidade dos bens em questão que determinam o preço, mas sua avaliação pelas partes em concorrência e suas tentativas de mudança e de resistência a essas avaliações.

Segundo Duzert (2007), o resultado de uma negociação deve poder satisfazer os valores e interesses de cada parte, atendendo aos valores e interesses que cada agente tentará impor à outra parte para fechamento do acordo. Em caso de fracasso, as partes simplesmente vão se retirar do acordo. Esses critérios da demanda fazem com que o resultado seja determinado pela avaliação subjetiva das partes e não pelas forças ocultas do mercado. Assim, os resultados negociados não derivam de algum equilíbrio definido de fora, mas desse jogo entre as duas partes e de seus esforços de demanda.

Zartman (2007) afirma que a definição do preço e outras condições em negociação não obedecem às funções matemáticas que podem ser transcritas em curvas regulares. Elas derivam de conjuntos desiguais e irregulares, que dão resultados mais pela seleção do que pela intersecção. Assim, as curvas de indiferença e de demanda não refletem uma situação de negociação. Além do mais, esses valores não podem ser medidos por meio de algumas variáveis quantitativas comuns. Os valores dos componentes da demanda estão essencialmente nas mãos das partes e são usados durante a negociação como elementos de decisão. A existência desses diferentes tipos de demanda priva o mecanismo da negociação de aspectos que fundamentam a clareza e a nitidez das teorias econômicas. Uma negociação é, portanto, um processo de identificação e de escolhas específicas a partir de uma situação de incerteza e não a combinação de posições fixas.

Ainda segundo Zartman (2007), os cinco princípios que descrevem as regras do jogo da prática da negociação, assim como o processo de busca de um resultado, são:

\section{a)Racionalidade}

Considerando que cada parte dispõe da mesma racionalidade, o resultado esperado vai sendo construído à medida que o processo de negociação vai avançando e o conhecimento específico é absorvido pela outra parte. É importante frisar que como uma das partes não tem certeza absoluta sobre as demandas e o poder da outra, ambas querem manter o outro num estado de informações imperfeitas e assim obter vantagem no acordo; 


\section{b)Soma positiva}

Já que as partes escolhem o resultado que melhor atende às suas necessidades individuais, elas não vão aceitar um resultado pré-negociado, a não ser que ele seja melhor ou superior ao seu "ponto de segurança" individual. Cada parte negociará, continuamente, a partir do seu ponto de segurança próprio e que se tornará o seu objetivo de referência na negociação;

c)Equivalência

As partes tendem a recusar um resultado negociado a menos que ele seja no mínimo equivalente ao já obtido por outras partes e considerado ponto de referência. Na negociação, esse resultado é o chamado "ponto de segurança" e serve como referência para as partes estabelecerem as condições mínimas do acordo que, no entanto, pode ser atualizado e flexibilizado por iniciativa de qualquer das partes em função do poder de demanda e de oportunidade;

\section{d)Reciprocidade}

Já que as partes se consideram em igualdade na negociação e procuram um resultado equivalente, aguardam que as concessões durante o processo de negociação sejam recíprocas. A aplicação da regra de reciprocidade aumenta a flexibilidade durante a negociação, contribuindo positivamente para o acordo;

\section{e)Distribuição}

Já que a negociação está ligada à tomada de decisão, as partes tentam primeiramente satisfazer seus próprios interesses antes de renunciar ao acordo, usando o direito de veto. A princípio, as partes têm em vista a melhor solução para todos, na medida em que também essa seja a melhor para elas. Esse resultado pode se revelar acidentalmente como a melhor solução, assim como pode ser uma solução ineficaz.

Pelos argumentos e teorias apresentadas, pode-se concluir que para a negociação atingir o acordo desejado ocorrem várias condições, sendo que do ponto de vista da racionalidade nota-se, por exemplo, as partes tentando limitar o ganho da outra ou não querendo compartilhá-lo. No caso da incerteza de ambas, ocorre o fenômeno da proteção, via cláusulas do contrato, com suas obrigações e limitações.

Segundo Zartman (2007), o único motivo para que uma parte fique interessada em um acordo eficaz é a maximização dos seus próprios ganhos e controle dos ganhos da outra parte. Se ambas as partes tiverem essa percepção durante o processo de negociação, $o$ contrato será celebrado e sua execução respeitada. Como na teoria e na prática econômica, os princípios da negociação são feitos para se obter a melhor e mais justa forma de transação. De comum acordo, as partes constituem um conjunto de regras de governança que servem para evitar um poder unilateral. Se durante a negociação esses princípios não forem tratados, alinhados e contratados adequadamente, o acordo corre o risco de fracassar.
Para Nelson (2004), os gestores da área de suprimentos das várias empresas participantes de uma cadeia devem saber o custo de seus produtos e processos para poder fazer negociações justas e equilibradas durante a etapa de negociação. Se os custos de servir todos os clientes, especialmente àqueles de larga escala e grandes volumes, são conhecidos, então melhores negociações, mais vantajosas, podem e devem ocorrer, trazendo como consequência relacionamentos mais firmes e duradouros. Esses relacionamentos devem aumentar a eficiência da cadeia de suprimentos, possibilitando uma melhor distribuição de tarefas e custos relacionados ao longo de toda a cadeia. Por último, um ambiente colaborativo e proativo pode permitir que as melhorias contínuas e as reduções de custo obtidas sejam comunicadas e aplicadas a todos os integrantes da cadeia, de forma a estreitá-la e perpetuá-la.

Se os gerentes e administradores da cadeia de suprimentos conhecerem somente os principais formadores de custo que incidem na fabricação de seus produtos, tais como: mão de obra, materiais diretos e indiretos, custos logísticos etc., isso não será suficiente para determinar com precisão a lucratividade. $\mathrm{O}$ que se deve ao fato de existirem outros custos envolvidos na transação que devem ser identificados e considerados de forma específica para determinação da lucratividade e, assim, do preço final de aquisição (COKINS, 1999).

\subsection{Custos de transação}

A abordagem dos custos de transação, criada por Robert Coase em 1937, procura compreender por que as empresas existem e fazem coisas ao invés de comprá-las de terceiros. Segundo Coase (1937), os custos de transação incluem os custos de coletar informações, os custos de negociação e os custos do estabelecimento de contratos.

Para North (1994), o alto preço da informação é a chave para os custos de transação, os quais consistem nos custos de medir os atributos de valor do bem que está sendo negociado mais os custos de proteção dos direitos, controle e aplicação dos contratos.

Em outras palavras pode-se considerar que os custos de transação incluem:

- Custos de coleta de informações sobre o negócio;

- Custos de negociação e estabelecimento do contrato;

- Custos de controle e de execução do contrato.

Dessa forma, a formação do custo de aquisição de um produto ou serviço é mais complexa do que apenas o preço do bem ou do serviço negociado. Outros custos, incluindo a pesquisa de preços e a transação em si, a negociação e o poder de barganha dos agentes envolvidos, a manutenção e o uso das informações privilegiadas (segredos comerciais), 
além dos custos de controle e execução, adicionam valor ao custo de aquisição. A viabilidade do bem ou serviço a ser entregue por uma empresa depende diretamente da detecção da somatória desses custos na determinação do valor do produto ou serviço no mercado.

Conforme Williamson e Masten (1985), os custos de transação são decorrentes de três atributos básicos que definem a transação: especificidade dos ativos, incerteza e frequência das transações, e de pressupostos comportamentais dos agentes envolvidos, a racionalidade limitada desses agentes e o oportunismo. Discute-se a seguir como cada um dos fatores acima pode influir na transação.

a) Especificidade dos ativos: Quanto mais complexos e de alto valor forem os ativos, mais complexos serão os contratos, justificados pelos maiores riscos envolvidos, acarretando maiores custos de transação. Segundo Williamson e Masten (1985), conforme a especificidade dos ativos aumenta, mais complexas devem ser as estruturas de governança e mais complexos se tornam os contratos, para atenuar falhas e o seu não cumprimento pelas partes e, portanto, maiores são os custos de transação;

b) Incerteza: Conforme Farina, Azevedo e Saes (1999), a incerteza determina os limites da racionalidade limitada, com reflexos na duração e complexidade dos contratos e, consequentemente, do custo. A incerteza, característica de uma transação, pode ser determinante na escolha de uma estrutura de governança;

c) Frequência das transações: A frequência também possui impacto nos custos de transação. Em decorrência da repetição da relação, as partes podem adquirir conhecimento umas das outras (reduzindo a incerteza), criando uma reputação em torno de uma marca e, em alguns casos, gerando compromisso confiável e continuidade de relação (FARINA; AZEVEDO; SAES, 1999); d) Racionalidade limitada: Segundo Williamson e Masten (1985), a racionalidade limitada dos agentes e dos tomadores de decisão, a assimetria da informação e a inabilidade de estabelecer completamente o comportamento dos agentes na presença de múltiplas contingências geram contratos incompletos, sujeitos a renegociações e possibilidade de comportamento oportunista; e) Comportamento oportunista: No que diz respeito ao "comportamento oportunista", como se considera que não há limite para o comportamento egoísta dos agentes, isso implica que uma parte pode impor perdas à outra durante a negociação. Ou seja, uma parte pode agir sem ética durante a negociação e antes da efetivação do contrato (oportunismo ex-ante) ou esse comportamento antiético pode ocorrer durante a vigência do contrato (oportunismo ex-post).
Conforme Rocha (2002), quando uma transação comercial ocorre de forma não instantânea, ou seja, quando não ocorre o pagamento e a imediata entrega da mercadoria correspondente, há a necessidade de um contrato com estabelecimento de direitos e deveres para os participantes da transação, inclusive com estabelecimento de cláusulas de controle e governança para monitoramento do que foi estabelecido entre as partes. Portanto, se uma negociação relativa a uma transação comercial não instantânea for conduzida de forma planejada e estruturada, incluindo mecanismos de controle e governança para o cumprimento do que foi estabelecido, poderá haver redução dos riscos decorrentes da incerteza e dos outros fatores geradores dos custos de transação.

\subsection{Métodos de cotação e negociação}

Segue a descrição das principais características dos métodos de cotação e negociação, segundo a literatura disponível.

\section{Solicitação de cotação ou RFQ (Request for Quote)}

Esse método de cotação e negociação, usual na cadeia de autopeças, baseia-se no envio aos fornecedores participantes do processo de cotação de um formulário chamado solicitação de cotação ou pelo nome mais conhecido de RFQ, o qual contém todas as informações básicas a respeito do componente, material ou serviço que se pretende adquirir, tal como especificação do material a ser adquirido, prazo de entrega, quantidade, local de entrega, entre outros.

Esse tipo de relacionamento é conhecido na literatura como arm's length e é adequado para situações em que os custos de transação, o valor e a tecnologia relacionados ao produto negociado são baixos (CORRÊA, 2010).

Com a devolução das solicitações preenchidas pelos fornecedores participantes do processo, o que na prática equivale à cotação de preços, o comprador faz as análises comparativas necessárias para decidir qual é a melhor proposta de fornecimento. Normalmente a solicitação de cotação que apresenta o menor preço é a escolhida após o comprador tentar obter alguma vantagem pela redução do preço ou melhoria das outras condições ofertadas usando como argumento o fechamento do negócio.

Esse método é um dos mais simples do ponto de vista do processo de compras, pois praticamente se limita a explorar as ofertas recebidas sem que haja possibilidade de grandes análises relativas ao custo real ou ao preço desejado para esse negócio. Normalmente, esse método também limita os fornecedores participantes do processo à região de atuação da firma que está liderando o processo de cotação, reduzindo a possibilidade de desenvolvimento de fontes provenientes de outras regiões ou países. 
Principais características desse método:

a) Processo de negociação pouco transparente;

b) Aumenta o poder de barganha do comprador;

c) Aplicável a bens e serviços comuns de pouca complexidade;

d) Aplicável a negócios frequentes e repetitivos;

e) Baixo nível de informações sobre o negócio.

\section{Solicitação de cotação ou RFQ (Request for Quote) com abertura de custos}

É uma variante mais desenvolvida do método solicitação de cotação já descrito em que há também a solicitação de inclusão de um formulário mostrando a planilha dos custos que levaram à elaboração do preço cotado na oferta, além do preenchimento do formulário RFQ.

De posse da planilha de custo aberto, o comprador poderá analisar todos os custos envolvidos na precificação do produto ou serviço tais como: mão de obra, matéria-prima, tempos de fabricação, custos gerais de fabricação, taxas horárias, custos de depreciação de bens de produção, custos de sucata e outras perdas de processo, custos logísticos e de embalagem, lucro etc.

Essa análise possibilitará ao comprador entender detalhes da cotação em termos de custos. Se ele tiver o conhecimento de análise de custos, poderá usá-lo na negociação do preço final apurando divergências ou disparidades no custo e preço informado na planilha e reduzindo os fatores de custo originados pela incerteza ou oportunismo, entre outros.

Principais características desse método:

a) Processo de negociação transparente através do custo aberto;

b) Aumenta o poder de barganha do comprador;

c) Aplicável a bens e serviços pouco complexos;

d) Regular nível de informação sobre o negócio.

\section{Global Sourcing ou cotação global}

Global Sourcing é o termo usado para descrever a prática de cotação de preços no mercado global para bens e serviços sem limitação de fronteiras da firma compradora, conforme Monczka, Trent e Handfield (2005). O processo de cotação e negociação de preços obtido a partir desse método permite explorar a competitividade global dos diversos mercados e pode ser aplicada para produtos e serviços. Essa competitividade inclui baixo custo da mão de obra, menor custo de matéria-prima e outros fatores como isenção de impostos e baixas tarifas de comércio. $\mathrm{O}$ exemplo clássico de aplicação da negociação utilizando o Global Sourcing é a cotação obtida em países do Extremo Oriente, particularmente China, Tailândia, Vietnã, entre outros, que têm preços menores que os praticados nos países ocidentais.

A comparação das cotações globais com as cotações de firmas locais causa uma tensão competitiva que, em muitos casos, obriga os fornecedores nacionais a reduzirem seus preços, de modo a se manterem competitivos e participando da cadeia de suprimentos.

Principais características desse método:

a) Processo de cotação e negociação pouco transparente;

b) Aumenta o poder de barganha do comprador;

c) Aplicável a bens e serviços comuns de pouca complexidade;

d) Aplicável a negócios frequentes e repetitivos;

e) Baixo nível de informação sobre o negócio.

E@procurement ou comércio eletrônico através da internet (B2B)

E@procurement, B2B (business to business) ou comércio eletrônico são os termos usados para definir o processo de cotação e negociação de preços feito através de softwares e sites especializados em comércio eletrônico usando a internet como forma de comunicação com os possíveis fornecedores do mercado, conforme definição de Baily (2008).

$\mathrm{O}$ método atende praticamente todas as etapas básicas de um processo de compras, incluindo: processo de pesquisa e seleção de fornecedores, solicitação da cotação de preços, negociação, colocação do pedido, contratação e acompanhamento do processo logístico de entrega e pagamento do preço acertado. Tudo é feito através da internet, sem praticamente troca de documentos físicos.

Tipicamente, o comércio eletrônico se dá através de sites que permitem que compradores devidamente qualificados e registrados procurem por produtos e fornecedores de bens e serviços também qualificados e registrados. Dependendo da abordagem escolhida, os compradores podem solicitar cotações de preços e os vendedores podem enviar suas ofertas diretamente através da internet. Os softwares de comércio eletrônico tornam possível automatizar compras de determinados produtos e serviços. Normalmente os softwares de comércio eletrônico incluem ainda a capacidade de realização de leilões reversos para negociação do preço e tomada da decisão da fonte de fornecimento.

Existem vários tipos de e@procurement ou comércio eletrônico:

- ERP (Enterprise Resource Planning) baseado na web: O ERP gera automaticamente as requisições de materiais e já as transforma em ordens de compra, enviando aos fornecedores via EDI;

- E-MRO (Maintenance, Repair and Operation): Idem acima, porém dirigido à geração automática de requisições e ordens de compra de materiais para manutenção, reparação e operação;

- E-sourcing: Busca de novos fornecedores usando a internet;

- E-tendering: Envio eletrônico de solicitações de cotação e informação para os fornecedores conhecidos e outros presentes na web.

Principais características desse método: 
a) Processo de negociação transparente através de leilão reverso;

b) Aplicável a bens e serviços comuns de pouca complexidade;

c) Processo de compra ágil, adequado a transações frequentes;

d) Alto nível de informação sobre o negócio.

Strategic Sourcing ou fornecimento estratégico

Strategic Sourcing ou processo estratégico de cotação é o método de cotação e negociação de preços que melhora e reavalia continuamente as atividades de compra da empresa, conforme Nishiguchi (1994).

O processo de cotação e compras chamado de Strategic Sourcing tem por objetivo a reavaliação e melhoria contínua das atividades de compras da empresa, buscando manter e melhorar a vantagem competitiva dos produtos e serviços adquiridos e assim manter e melhorar sua vantagem competitiva. O processo do Strategic Sourcing popularizou-se na década de 1990, sendo implementado em grandes empresas americanas chamadas de Blue Chips. Essa metodologia também é utilizada por empresas de consultoria para reavaliação de negócios e como ferramenta em programas de melhoria contínua, com o objetivo de reduzir custos e aumentar a competitividade da cadeia de suprimentos em questão.

As etapas básicas do processo de Strategic Sourcing são: mapeamento de todas as despesas do produto; mapeamento de todo o mercado fornecedor; análise do custo total (incluindo o custo objetivo do bem ou serviço); identificação dos possíveis fornecedores; desenvolvimento da estratégia de cotação e negociação; negociação com os fornecedores e definição da fonte de fornecimento; implementação da nova estrutura de fornecimento; controle dos resultados esperados e aplicação de plano de correção, se necessário; e, por último, reinício do processo.

Principais características desse método:

a) Processo de negociação transparente através da análise do custo total;

b) Neutraliza o poder de barganha do comprador;

c) Aplicável a bens e serviços complexos;

d) Alto nível de informação sobre o negócio.

\section{Total Cost of Ownership (TCO) ou custo total de aquisição}

É o método de cotação e negociação de preços que permite determinar os custos totais envolvidos na aquisição de um produto, bem ou serviço considerando todos os custos diretos e indiretos envolvidos na transação (ELLRAM, 1994). Utiliza conceitos de gerenciamento contábil que permitem a análise do custo total e até mesmo do custo social. Os conceitos do TCO foram desenvolvidos pela empresa de consultoria Gartner Group em meados da década de 1980.

Normalmente, a negociação comercial usa o preço líquido ofertado como base da negociação, isto é, o preço de compra de um produto, bem ou serviço ex-impostos, sem a inclusão de custos logísticos e outros. Porém, para efeito do custo total de aquisição, esses e outros custos devem ser considerados para que a decisão de compra seja, de fato, aquela que representa a de menor custo total de aquisição.

Para tanto, o processo de cotação e negociação deverá considerar, além do preço, outros custos diretos e indiretos envolvidos na aquisição, tais como custos financeiros, custos logísticos, custos de garantia, custos administrativos e custos de oportunidade, entre outros.

Esse método tem se difundido rapidamente por ser aquele que reflete melhor o custo total de aquisição e também por incluir certos aspectos circunstanciais como, por exemplo, os custos logísticos oriundos da importação e do comércio exterior que, não sendo considerados adequadamente, podem levar a uma decisão errada, pois a importação de um item pode apresentar um preço na origem menor do que o item nacional, porém quando são considerados todos os custos decorrentes dos impostos mais os custos logísticos para a importação ele poderá resultar em um preço final superior.

Principais características desse método:

a) Processo de negociação transparente através da análise do custo total;

b) Aumenta o poder de barganha do comprador;

c) Aplicável a bens e serviços complexos;

d) Processo de compra demorado e complexo;

e) Alto nível de informação sobre o negócio.

\section{Administração de contratos}

Administração ou gerenciamento de contratos é o método pelo qual se negocia e se estabelece um contrato de fornecimento com clientes, fornecedores, parceiros, empregados etc., conforme definição da International Association for Contract and Commercial Management - IACCM, (INTERNATIONAL..., 2010). Esse gerenciamento inclui a fase de cotação e negociação dos termos e condições, com a definição dos direitos e deveres das partes envolvidas na transação. Além das cláusulas negociadas, o contrato inclui os termos de eventuais tolerâncias e alterações que podem ocorrer durante a sua implantação ou execução.

O contrato é a formalização de uma negociação ocorrida entre duas ou mais partes devidamente identificadas e qualificadas com o objetivo de executar as metas estabelecidas no acordo. Um pré-requisito para cumprimento do contrato, entre outras coisas, é que todas as partes aceitem os termos e condições 
estabelecidos. Essa aceitação se dá através da assinatura das vias do contrato pelas partes. Porém, com o advento do comércio eletrônico, outras formas de formalização do contrato estão sendo consideradas sem que haja um documento formalmente assinado.

No caso específico da cadeia de suprimentos automotiva, contrato de compra é o instrumento firmado entre uma firma compradora e uma firma fornecedora que se compromete a vender produtos ou serviços de acordo com os termos e condições negociados e pactuados. Normalmente, os contratos de compra suportam transações relativas à prestação de serviços, compra de bens de ativo fixo, prestação de serviços de consultoria, fornecimento de materiais indiretos etc., nos quais os parâmetros de controle e medição não são perfeitamente tangíveis como, por exemplo, a medição da qualidade do serviço de limpeza de escritórios.

Outro exemplo do uso e aplicação de contratos de compra ou fornecimento refere-se às compras de matérias-primas chamadas commodities como, por exemplo, cobre e alumínio, minério de ferro, celulose, produtos químicos, combustíveis etc. Por se tratar de materiais comuns a vários ramos de atividade e por serem fornecidos por muitas firmas em todo o mundo, seu preço de venda flutua em função da oferta e da demanda nos vários mercados globais. Nesse caso, o contrato de fornecimento assegura, para ambas as partes, garantia de demanda e abastecimento, conferindo vantagem competitiva à cadeia de suprimentos e evitando a geração de compras spot ou únicas - situação que permite a ocorrência de oportunismo e incerteza, gerando custos extraordinários.
Principais características desse método:

a) Processo de negociação transparente, baseado em contrato negociado;

b) Aplicável a bens e serviços pouco complexos;

c) Alto nível de informação sobre o negócio.

O Quadro 1 resume as características principais dos métodos de cotação e negociação predominantes na cadeia de suprimentos de autopeças.

\subsection{Hipóteses}

A partir das características comuns aos métodos de cotação e negociação predominantes na cadeia de suprimentos de autopeças, as seguintes hipóteses foram feitas acerca de sua influência nos custos de transação:

H1 - A transparência no processo de cotação e negociação de produtos, bens ou serviços resulta em menores custos de transação.

$\boldsymbol{H} \mathbf{2}$ - Em um processo de cotação e negociação de produtos, bens ou serviços, os custos de transação serão menores se o comprador tiver poder de barganha no negócio.

H3 - Em processos de cotação e negociação de produtos, bens ou serviços muito específicos e complexos, o custo da transação tenderá a ser maior.

$\boldsymbol{H 4}$ - Negócios repetitivos e frequentes permitem que o processo de cotação e negociação de produtos, bens ou serviços resulte em menores custos de transação.

H5 - O processo de cotação e negociação de produtos, bens ou serviços com baixo nível de informações gera incertezas que resultam em maiores custos de transação.

Quadro 1. Classificação dos métodos de cotação e negociação segundo suas características.

\begin{tabular}{|c|c|c|c|c|c|c|c|}
\hline & $\begin{array}{l}\text { RFQ sem } \\
\text { abertura } \\
\text { de custos }\end{array}$ & $\begin{array}{c}\text { RFQ com } \\
\text { abertura } \\
\text { de custos }\end{array}$ & $\begin{array}{c}\text { Global } \\
\text { Sourcing }\end{array}$ & $\begin{array}{c}E @ \\
\text { procurement } \\
\text { (comércio } \\
\text { eletrônico) }\end{array}$ & $\begin{array}{l}\text { Strategic } \\
\text { Sourcing }\end{array}$ & TCO & $\begin{array}{c}\text { Administração } \\
\text { de contratos }\end{array}$ \\
\hline $\begin{array}{l}\text { Transparência } \\
\text { no processo de } \\
\text { negociação }\end{array}$ & Pouca & Média & Pouca & Alta & Alta & Alta & Alta \\
\hline $\begin{array}{l}\text { Influência do poder } \\
\text { de barganha do } \\
\text { comprador }\end{array}$ & Alta & Alta & Alta & Neutra & Neutra & Alta & Neutra \\
\hline $\begin{array}{l}\text { Aplicabilidade a } \\
\text { bens ou serviços } \\
\text { complexos }\end{array}$ & Não & Não & Não & Não & Sim & Sim & Não \\
\hline $\begin{array}{l}\text { Aplicabilidade a } \\
\text { negócios repetitivos } \\
\text { ou frequentes }\end{array}$ & Sim & Sim & Sim & Sim & Não & Não & Não \\
\hline $\begin{array}{l}\text { Nível de informação } \\
\text { sobre o negócio }\end{array}$ & Baixo & Regular & Baixo & Alto & Alto & Alto & Alto \\
\hline
\end{tabular}

Fonte: autores. 


\section{A pesquisa}

\subsection{Metodologia}

O objetivo principal desta pesquisa foi identificar quais métodos de cotação e negociação são mais empregados na cadeia de suprimentos de autopeças brasileira. Como objetivo secundário, procurou-se obter subsídios para responder de que forma as características dos métodos de cotação e negociação mais utilizados na cadeia de suprimentos de autopeças brasileira afetam os custos de transação.

A abordagem utilizada na pesquisa foi do tipo quantitativa, sendo realizada com as 100 maiores empresas de autopeças do Brasil, conforme classificação do Sindipeças/Abipeças - Desempenho do Setor de Autopeças (SINDICATO..., 2009-2010). $\mathrm{Na}$ primeira parte empregou-se como técnica para obtenção de dados o levantamento através de questionário com perguntas fechadas de múltipla escolha, procurando-se identificar o método de negociação mais utilizado pelas empresas para a compra de cada um dos grupos de materiais utilizados na cadeia de autopeças, segundo a classificação utilizada pela metodologia de cálculo do Índice Geral de Preços - Disponibilidade Interna (IGP-DI) da Fundação Getúlio Vargas. Na segunda parte da pesquisa empregou-se questionário utilizando escala de Likert, de 1: concordo totalmente até 5: discordo totalmente, com objetivo de se identificar a percepção dos executivos de supply chain das empresas pesquisadas acerca da influência das características dos métodos de cotação e negociação predominantes na cadeia de suprimentos de autopeças nos custos de transação, segundo as hipóteses formuladas.

O questionário de pesquisa foi enviado por $e$-mail aos executivos de supply chain das empresas à montante das montadoras de veículos, ou seja, aos integrantes da cadeia de suprimentos de autopeças, limitado aos denominados "sistemistas" e aos fornecedores desses, denominados tier 1 . As empresas pesquisadas foram também classificadas em função do porte, segundo seu faturamento anual em reais e segundo a origem do capital majoritário, nacional ou multinacional. O questionário foi testado para fins de validação, tendo sido enviado previamente a cinco executivos de supply chain do relacionamento profissional do pesquisador, o que gerou aperfeiçoamentos na terminologia e na formatação inicial.

Dos 100 questionários enviados obteve-se resposta de 51 empresas, sendo 36 de capital multinacional, representando $69 \%$ do universo de respondentes, e 15 de capital nacional, equivalente a $31 \%$ do total de respostas recebidas.

Segundo Fávero et al. (2009), se a variável for qualitativa e a população finita, o tamanho da amostra (n) aleatória simples pode ser calculado pela seguinte fórmula:

$$
n=\frac{z_{g}^{2} \cdot \hat{p} \cdot \hat{q} \cdot N}{e^{2}(N-1)+z_{g}^{2} \cdot \hat{p} \cdot \hat{q}}
$$

onde

$\mathrm{Z}_{\mathrm{g}}=$ abscissa da distribuição normal padrão, fixando um nível de confiança g;

$\hat{p}=$ estimativa da proporção $\mathrm{p}$;

$\hat{q}=1-\hat{p}$;

$\mathrm{N}=$ tamanho da população;

$e^{2}=$ erro amostral (máxima diferença permitida entre $\hat{p}$ e $\hat{q}$ ).

Para avaliar a amostragem da pesquisa, adotou-se: $\mathrm{Z}_{\mathrm{g}}=1,96$ (onde g: $95 \%$ ), $\hat{p} . \hat{q}=0,25, \mathrm{~N}=100, e^{2}=10 \%$ que, aplicados à fórmula acima, resultaram numa amostra de 49, representativa para os 100 questionários enviados.

Ressalte-se que esse cálculo foi feito somente para se avaliar a representatividade da amostra obtida, a posteriori, cabendo a ressalva da sua não aleatoriedade.

\subsection{Resultados}

\subsubsection{Métodos de negociação mais empregados na cadeia de autopeças}

A tabulação dos dados relativos aos métodos de cotação e negociação foi feita através da distribuição percentual das respostas pelas respectivas opções, agrupando-se todas as empresas, sem distinção da origem do capital e da faixa de faturamento anual, conforme mostrado na Tabela 1:

Analisando-se os dados da Tabela 1 observa-se que o método mais empregado na cadeia de suprimentos de autopeças brasileiro é o da solicitação de cotação RFQ sem abertura de custo que, independentemente

Tabela 1. Tabulação dos dados relativos aos métodos de cotação e negociação.

\begin{tabular}{ccc}
\hline Métodos de cotação e negociação & Respostas & \% \\
\hline RFQ sem custo aberto & 160 & 43 \\
RFQ com custo aberto & 79 & 21 \\
Global Sourcing & 59 & 16 \\
Strategic Sourcing & 31 & 8 \\
Contratos & 23 & 6 \\
Total Cost of Ownership & 10 & 3 \\
E@ procurement & 9 & 2 \\
Total geral & 371 & 100 \\
\hline
\end{tabular}

O número de respostas é maior do que o número de empresas respondentes uma vez que uma mesma empresa pode utilizar-se de diferentes métodos para a compra de cada um dos materiais utilizados na cadeia de autopeças. 
do tipo de material em cotação, é utilizado em $43 \%$ dos casos. O segundo método de cotação e negociação de preços, selecionado por $21 \%$ dos respondentes, foi o da solicitação de cotação RFQ com abertura de custo. Em terceiro lugar apareceu o método Global Sourcing, com $16 \%$ da preferência.

Esse resultado demonstra que os métodos mais simples e menos estruturados do ponto de vista do processo de cotação e negociação prevalecem, pois não requerem grandes investimentos em equipes negociadoras treinadas e aptas ao tipo de negociação e relacionamento que os métodos mais estruturados requerem, como, por exemplo, base de fornecimento composta por fornecedores locais e globais, capacidade de elaborar contratos complexos, criação de condições para manter o relacionamento com os parceiros da cadeia de suprimentos no longo prazo, capacidade de comunicação e administração de transações internacionais do ponto de vista financeiro e administrativo, entre outras.

Para entender as diferenças de comportamento e utilização dos métodos de cotação e negociação em função da origem do capital e do tamanho da empresa pelo seu faturamento, foram analisadas as respostas considerando essas classificações.

Na Tabela 2 estão apresentados os métodos de cotação e negociação predominantes na cadeia de suprimentos de autopeças, separados pela origem do capital das empresas respondentes, supondo-se que as empresas de capital multinacional têm uma estrutura mais organizada na área de supply chain, pois participam de cadeias de suprimentos globais, mais desenvolvidas e competitivas, sendo, portanto, obrigadas a desenvolver estratégias mais competitivas para seus negócios, utilizando métodos de cotação e negociação mais estruturados, que permitem melhores resultados e menores custos finais.

Analisando-se os dados da Tabela 2 pode-se constatar que as empresas de capital nacional são as que utilizam os métodos mais simples, como o do RFQ sem abertura de custo, em maior porcentagem. $\mathrm{Na}$ mesma tabela se confirma que as empresas de capital multinacional utilizam uma gama mais variada, estruturada e desenvolvida de métodos de cotação e negociação.

Observa-se que as empresas de capital nacional utilizam predominantemente o método do RFQ sem abertura de custo, com $66 \%$ das respostas; em segundo lugar ficou o método do RFQ com custo aberto, com 19\% das respostas. Por outro lado, nota-se uma distribuição de respostas diferente nas empresas de capital multinacional respondentes, ou seja, elas utilizam um leque de métodos mais amplo e desenvolvido e com melhor distribuição, apresentando RFQ sem abertura de custo 33\% das respostas; RFQ com abertura de custo $22 \%$ das respostas; Global Sourcing 20\%; e Strategic Sourcing 11\%; esses quatro métodos perfazem $86 \%$ das respostas. Excluindo-se o RFQ sem abertura de custo do total acima, resulta que os outros três métodos perfazem 53\% do total das respostas, sendo que esses três métodos têm características especificas que permitem classificá-los como melhor estruturados.

Na Tabela 3, as respostas foram classificadas segundo o método de cotação e negociação considerando o faturamento anual das empresas respondentes. Supõe-se que as empresas de maior faturamento atingiram um grau de desenvolvimento e maturidade maior no processo de negociação devido à melhor estruturação administrativa e gerencial na área de supply chain, dentre outras características de caráter técnico, comercial ou administrativo. Considere-se ainda o fato de que as maiores empresas de autopeças por faturamento, geralmente, fornecem sistemas completos às montadoras de automóveis que estão no topo da cadeia automotiva, onde a competência e competitividade técnica e comercial sustentam e garantem a participação no supply chain automotivo.

Da simples observação da Tabela 3 pode-se notar que as empresas com faturamento maior do que $\mathrm{R} \$ 600$ milhões utilizam uma gama maior de métodos de cotação e negociação, com menor ênfase no método do RFQ sem abertura de custo. Os quatro métodos: RFQ com e sem custo aberto, Global Sourcing e

Tabela 2. Métodos de cotação e negociação predominantes na cadeia de suprimentos de autopeças classificados pela origem do capital.

\begin{tabular}{lcccc}
\hline \multirow{2}{*}{ Métodos de cotação e negociação } & \multicolumn{2}{c}{ Capital multinacional } & \multicolumn{2}{c}{ Capital nacional } \\
\cline { 2 - 5 } & Respostas & \% & Respostas & \% \\
\hline RFQ sem custo aberto & 84 & 33 & 76 & 66 \\
RFQ com custo aberto & 57 & 22 & 22 & 19 \\
Global Sourcing & 51 & 11 & 8 & 7 \\
Strategic Sourcing & 28 & 7 & 4 & 3 \\
Contratos & 19 & 4 & 0 & 0 \\
Total Cost of Ownership & 10 & 2 & 2 & 2 \\
E@ procurement & 6 & 100 & 116 & 100 \\
Total geral & 255 &
\end{tabular}


Tabela 3. Métodos de cotação e negociação predominantes na cadeia de suprimentos de autopeças agrupados pelo faturamento das empresas respondentes (milhões de reais).

\begin{tabular}{lcccccc}
\hline & \multicolumn{2}{c}{ Faturamento $<$ 200 } & \multicolumn{2}{c}{$\mathbf{2 0 0}<$ Fat. $<600$} & \multicolumn{2}{c}{ Faturamento $>\mathbf{6 0 0}$} \\
\hline Métodos de cotação e negociação & Respostas & $\mathbf{\%}$ & Respostas & $\mathbf{\%}$ & Respostas & $\%$ \\
\hline RFQ sem custo aberto & 92 & 58 & 43 & 44 & 25 & 22 \\
RFQ com custo aberto & 26 & 16 & 26 & 27 & 27 & 23 \\
Global Sourcing & 21 & 13 & 10 & 10 & 28 & 24 \\
Strategic Sourcing & 6 & 4 & 6 & 6 & 19 & 17 \\
Contratos & 11 & 7 & 4 & 4 & 8 & 7 \\
Total Cost of Ownership & 3 & 2 & 4 & 4 & 4 & 3 \\
E@ @rocurement & 0 & 0 & 4 & 4 & 4 & 3 \\
Total geral & 159 & 100 & 97 & 100 & 115 & 100 \\
\hline
\end{tabular}

Strategic Sourcing totalizam $86 \%$ das respostas, sendo que o método Global Sourcing superou os outros métodos, com $24 \%$ da preferência.

À medida que o faturamento diminui, nota-se que o método do RFQ sem abertura de custo torna-se o preferido, ainda que a utilização dos outros métodos continue aparecendo de forma importante. Isso posto, pode-se concluir que as maiores empresas em termos de faturamento anual utilizam métodos mais estruturados e desenvolvidos de cotação e negociação de preços que as empresas de menor faturamento.

\subsubsection{Características dos métodos e sua influência nos custos de transação}

Nessa fase da pesquisa empregou-se questionário utilizando escala de Likert, de 1: concordo totalmente até 5: discordo totalmente, com objetivo de identificar a percepção dos executivos de supply chain das empresas pesquisadas acerca da influência das características dos métodos de cotação e negociação predominantes na cadeia de suprimentos de autopeças nos custos de transação, segundo as hipóteses formuladas. A Tabela 4 apresenta a distribuição percentual das respostas obtidas.

Para a hipótese H1, 88\% dos respondentes concordam ou concordam totalmente que a transparência no processo de cotação e negociação resulta em custos de transação menores. O mesmo resultado foi obtido para a hipótese $\mathbf{H 2}$, sendo que $88 \%$ dos respondentes também concordam ou concordam totalmente que o poder de barganha do comprador resulta em custos de transação menores no processo de cotação e negociação. $\mathrm{O}$ resultado obtido para a hipótese $\mathbf{H 3}$, segundo a qual produtos e serviços muito específicos e complexos resultam em custos de transação maiores no processo de cotação e negociação mostra neutralidade na percepção dos executivos quanto a essa relação. Isso provavelmente ocorre devido ao fato de as empresas com processos de cotação e negociação melhor estruturados já possuírem a estrutura de governança necessária para o gerenciamento de contratos mais complexos, não sendo percebidos custos de transação adicionais, ao contrário das empresas com processos de cotação e negociação não estruturados. Para a hipótese H4, o resultado obtido mostra que $66 \%$ dos respondentes concordam ou concordam totalmente que negócios repetitivos e frequentes levam a menores custos de transação no processo de cotação e negociação. Chama a atenção no resultado desse item a elevada porcentagem $(18 \%)$ de respondentes que discorda dessa afirmativa, todos representantes de empresas de capital multinacional. A explicação para esse resultado pode estar no fato de as empresas de capital multinacional utilizarem métodos de cotação e negociação mais estruturados, como indicado nos resultados da primeira parte da pesquisa. Nesses casos, a diminuição das incertezas resultante da repetição dos negócios é menos percebida, uma vez que os agentes acabam por fazer um contrato de fornecimento por prazo indeterminado para itens padronizados, com preços e condições de fornecimento firmes, como contrapartida da garantia de exclusividade de compra dos itens desse contrato. Para a hipótese H5, o resultado indica que $67 \%$ dos respondentes concordam ou concordam totalmente com a afirmativa de que baixos níveis de informação sobre o negócio resultam em maiores custos de transação.

As hipóteses foram testadas com base nos resultados obtidos utilizando-se a estatística t de Student, cujos resultados estão na Tabela 5 .

O teste ANOVA aplicado às respostas obtidas das empresas segundo sua faixa de faturamento não mostra diferenças significativas nas médias, conforme Tabela 6.

$\mathrm{O}$ teste $\mathrm{t}$ aplicado às respostas obtidas das empresas segundo a origem do capital mostra diferença significativa apenas na média da característica negócios repetitivos, correspondente à hipótese $\mathbf{H 4}$, conforme Tabela 7. A explicação para essa diferença pode estar no fato de as empresas de capital multinacional já utilizarem métodos de cotação e negociação mais estruturados, deixando de perceber a diminuição das incertezas resultante de negócios repetitivos, conforme já discutido anteriormente. 
Tabela 4. Características dos métodos de cotação e negociação e sua influência nos custos de transação.

\begin{tabular}{|c|c|c|c|c|c|c|c|c|}
\hline \multirow[b]{3}{*}{ Hipótese } & \multirow[b]{3}{*}{ Resposta } & \multirow{2}{*}{\multicolumn{3}{|c|}{$\begin{array}{c}\text { Capital multinacional } \\
\text { Faturamento }(\mathrm{R} \$ \text { milhões })\end{array}$}} & \multirow{2}{*}{\multicolumn{3}{|c|}{$\begin{array}{c}\text { Capital nacional } \\
\text { Faturamento }(\mathrm{R} \$ \text { milhões })\end{array}$}} & \multirow{3}{*}{$\begin{array}{l}\text { Total } \\
\text { geral }\end{array}$} \\
\hline & & & & & & & & \\
\hline & & $<200$ & $<600$ & $>600$ & $<\mathbf{2 0 0}$ & $<600$ & $>600$ & \\
\hline \multirow[t]{5}{*}{ H1 } & Concordo totalmente & $42 \%$ & $27 \%$ & $58 \%$ & $55 \%$ & $25 \%$ & $100 \%$ & $45 \%$ \\
\hline & Concordo & $42 \%$ & $55 \%$ & $33 \%$ & $45 \%$ & $50 \%$ & - & $43 \%$ \\
\hline & Não concordo nem discordo & $8 \%$ & $18 \%$ & $8 \%$ & - & - & - & $8 \%$ \\
\hline & Discordo & $8 \%$ & - & - & - & $25 \%$ & - & $4 \%$ \\
\hline & Discordo totalmente & - & - & - & - & - & - & - \\
\hline \multirow[t]{5}{*}{ H2 } & Concordo totalmente & $42 \%$ & $30 \%$ & $54 \%$ & $55 \%$ & $25 \%$ & $100 \%$ & $45 \%$ \\
\hline & Concordo & $42 \%$ & $60 \%$ & $31 \%$ & $45 \%$ & $50 \%$ & - & $43 \%$ \\
\hline & Não concordo nem discordo & $8 \%$ & $10 \%$ & $15 \%$ & - & - & - & $8 \%$ \\
\hline & Discordo & $8 \%$ & - & - & - & $25 \%$ & - & $4 \%$ \\
\hline & Discordo totalmente & - & - & - & - & - & - & - \\
\hline \multirow[t]{5}{*}{ H3 } & Concordo totalmente & $8 \%$ & - & - & $9 \%$ & - & - & $4 \%$ \\
\hline & Concordo & $33 \%$ & $50 \%$ & $31 \%$ & $36 \%$ & - & $100 \%$ & $35 \%$ \\
\hline & Não concordo nem discordo & $17 \%$ & $10 \%$ & $23 \%$ & $27 \%$ & $25 \%$ & - & $20 \%$ \\
\hline & Discordo & $33 \%$ & $40 \%$ & $46 \%$ & $27 \%$ & $75 \%$ & - & $39 \%$ \\
\hline & Discordo totalmente & $8 \%$ & - & - & - & - & - & $2 \%$ \\
\hline \multirow[t]{5}{*}{ H4 } & Concordo totalmente & - & $20 \%$ & - & $36 \%$ & $25 \%$ & $38 \%$ & $16 \%$ \\
\hline & Concordo & $50 \%$ & $50 \%$ & $54 \%$ & $45 \%$ & $75 \%$ & $50 \%$ & $51 \%$ \\
\hline & Não concordo nem discordo & $17 \%$ & $10 \%$ & $23 \%$ & $18 \%$ & - & $13 \%$ & $16 \%$ \\
\hline & Discordo & $33 \%$ & $20 \%$ & $23 \%$ & - & - & - & $18 \%$ \\
\hline & Discordo totalmente & - & - & - & - & - & - & - \\
\hline \multirow[t]{5}{*}{ H5 } & Concordo totalmente & $25 \%$ & $10 \%$ & $8 \%$ & $9 \%$ & $25 \%$ & - & $14 \%$ \\
\hline & Concordo & $42 \%$ & $60 \%$ & $69 \%$ & $45 \%$ & $50 \%$ & - & $53 \%$ \\
\hline & Não concordo nem discordo & $8 \%$ & $10 \%$ & $8 \%$ & $18 \%$ & - & - & $10 \%$ \\
\hline & Discordo & $25 \%$ & $20 \%$ & $8 \%$ & $27 \%$ & $25 \%$ & $100 \%$ & $22 \%$ \\
\hline & Discordo totalmente & - & - & $8 \%$ & - & - & - & $2 \%$ \\
\hline
\end{tabular}

Tabela 5. Teste t de Student para a média das amostras.

\begin{tabular}{lcrcc}
\hline \multicolumn{1}{c}{ Características } & Média* & $\mathbf{t}^{* *}$ & pvalor & Resultado \\
\hline Transparência na negociação (H1) & 1,71 & $-11,816$ & 0,0000 & Confirmada \\
Poder de barganha comprador (H2) & 1,71 & $-11,816$ & 0,0000 & Confirmada \\
Especificidade/complexidade (H3) & 3,00 & 0,000 & 1,0000 & Não confirmada \\
Negócios repetitivos (H4) & 2,35 & $-4,836$ & 0,0000 & Confirmada \\
Falta de informações (H5) & 2,45 & $-3,751$ & 0,0005 & Confirmada \\
\hline
\end{tabular}

*"Que características contribuem para a redução do custo de transação". (1) concordo totalmente; (5) discordo totalmente. ** Teste t para uma amostra $(\mathrm{H} 0:$ média $=3)$.

Tabela 6. ANOVA para comparação de médias de três populações.

\begin{tabular}{|c|c|c|c|c|c|}
\hline \multicolumn{6}{|c|}{ Faturamento ( $R$ \$ milhões) } \\
\hline Características & $<200$ & $<600$ & $>600$ & $\mathbf{F}$ & Sig. \\
\hline Transparência na negociação & 1,652 & 1,929 & 1,571 & 0,8226 & 0,4454 \\
\hline Poder de barganha comprador & 1,652 & 1,929 & 1,571 & 0,8226 & 0,4454 \\
\hline Especificidade/complexidade & 2,870 & 3,143 & 3,071 & 0,3647 & 0,6963 \\
\hline Negócios repetitivos & 2,348 & 2,143 & 2,571 & 0,6962 & 0,5034 \\
\hline Falta de informações & 2,478 & 2,357 & 2,500 & 0,0767 & 0,9263 \\
\hline Tamanho da amostra & 23 & 14 & 14 & & \\
\hline
\end{tabular}


Tabela 7. Teste t de Student para igualdade de médias.

\begin{tabular}{lcccc}
\hline \multicolumn{1}{c}{ Características } & Origem do capital & & S & Sig. \\
\hline Transparência na negociação & 1,743 & 1,625 & 0,4893 & 0,6284 \\
Poder de barganha comprador & 1,743 & 1,625 & 0,4893 & 0,6284 \\
Especificidade/complexidade & 3,029 & 2,938 & 0,3009 & 0,7656 \\
Negócios repetitivos & 2,629 & 1,750 & 3,7627 & 0,0005 \\
Falta de informações & 2,371 & 2,625 & 0,7850 & 0,4391 \\
Tamanho da amostra & 35 & 16 & & \\
\hline
\end{tabular}

\section{Conclusões}

Este trabalho teve como objetivo principal identificar os métodos de cotação e negociação de preços mais utilizados na cadeia de suprimentos de autopeças brasileira. Procurou-se também obter subsídios para identificar de que forma as características dos métodos de cotação e negociação mais utilizados afetam os custos de transação.

O interesse recaiu sobre a cadeia de suprimentos de autopeças devido à sua complexidade, atualização tecnológica e crescimento acentuado nos últimos anos e pelo fato de ela integrar a cadeia de suprimentos automotiva, que está entre aquelas de maior competitividade em termos de indústria de manufatura, dada a exposição e participação dos agentes pertencentes às cadeias de suprimentos globais atuantes em mercados abertos e altamente competitivos.

A pesquisa foi enviada através de $e$-mail aos gestores da área de supply chain das 100 maiores empresas de autopeças do Brasil, classificadas pelo seu faturamento anual e enquadradas nas categorias sistemista e tier 1, conforme catálogo do Sindipeças/ Abipeças - Desempenho do Setor de Autopeças (SINDICATO..., 2009-2010), e limitou-se aos métodos de cotação e negociação empregados na aquisição de materiais diretos de produção, deixando de lado os métodos empregados na aquisição de materiais indiretos e serviços, haja vista que nesse segmento o valor do material direto adquirido representa em média $90 \%$ do total.

Analisando-se os resultados da pesquisa sobre os métodos de cotação e negociação mais utilizados na cadeia de suprimentos de autopeças brasileira, pôde-se concluir que as empresas de capital multinacional e de maior faturamento utilizam, nas cotações e negociações, um leque maior de métodos de cotação e negociação mais estruturados do que aqueles utilizados pelas empresas nacionais e de menor porte. Pode-se afirmar isso tendo-se por base o resultado reportado nas Tabelas 2 e 3 , respectivamente, que mostram que as empresas de maior porte e de capital multinacional utilizam, praticamente na mesma proporção, os métodos RFQ com e sem abertura de custo, Global Sourcing e Strategic Sourcing, ao passo que as empresas nacionais e de menor porte utilizam predominantemente o método de cotação e negociação RFQ sem abertura de custo, que é um método mais simples e pouco estruturado do ponto de vista da cadeia de suprimentos. Isso se dá, provavelmente, devido à falta de agentes capacitados e treinados nos métodos mais sofisticados, falta de conhecimento e atuação em mercados e cadeias de fornecimento globais mais competitivas. Pode haver ainda outras causas, a serem investigadas, ligadas à origem das montadoras de veículos que muitas vezes trazem fornecedores de autopeças de suas cadeias de suprimento do exterior, não dando assim oportunidade para os fornecedores nacionais conquistarem novos negócios e aperfeiçoarem seus processos.

A partir desse resultado foram identificadas as principais características comuns encontradas nesses métodos e qual seu efeito nos custos de transação, segundo os executivos de supply chain das empresas pesquisadas. Verificou-se que as hipóteses segundo as quais as características transparência na negociação, poder de barganha do comprador e aplicabilidade a negócios repetitivos ou frequentes implicam em menores custos de transação foram confirmadas, assim como a hipótese segundo a qual a característica baixo nível de informações sobre o negócio tende a gerar maiores custos de transação. A hipótese segundo a qual a especificidade/complexidade dos ativos gera maiores custos de transação não foi confirmada, o que pode ser explicado, a princípio, pelo fato de as empresas com processos de cotação e negociação melhor estruturados já possuírem a estrutura de governança necessária para o gerenciamento de contratos mais complexos, não sendo percebidos custos de transação adicionais, ao contrário das empresas com processos de cotação e negociação não estruturados.

Acredita-se que os resultados deste trabalho tenham colaborado para a melhor compreensão dos processos de negociação na cadeia de suprimentos de autopeças, fornecendo dados relevantes aos gestores para a melhoria do relacionamento comercial na cadeia de autopeças e para o desenvolvimento de novas pesquisas. Um caminho sugerido para novas pesquisas seria ampliar o universo da análise, expandindo a amostragem a toda a cadeia de suprimentos automotiva, 
incluindo-se os OEM e os tier 2 e 3. Convém lembrar que, além de incluir todos os membros da cadeia automotiva, poderiam ser questionados todos os agentes envolvidos no processo de cotação e negociação da cadeia, ou seja, os compradores e os vendedores das empresas envolvidas na transação. Soluções para minimizar efeitos negativos de cada um dos métodos também poderiam ser discutidas pelos gestores e serem objeto de novas pesquisas.

\section{Referências}

BAILY, P. J. H. Procurement principles and management. Harlow: Prentice Hall Financial Times, 2008.

COASE, R. H. The nature of the firm. Economica, New Series, v. 4, n. 16, p. 386-405, nov. 1937. http://dx.doi. org/10.1111/j.1468-0335.1937.tb00002.x

COKINS, G. Are all of your trading partners worth it to you? achieving supply chain excellence through technology. Montgmorey Research, 1999.

CORRÊA, H. L. Gestão de redes de suprimento: integrando cadeias de suprimento no mundo globalizado. São Paulo: Atlas, 2010.

COYLE, J. J.; BARDI, E. J.; LANGLEY JUNIOR, J. The management of business logistics: a supply chain perspective. 7. ed. Toronto: Thomson Learning, 2003.

DUZERT, Y. Manual de Negociações Complexas. 2. ed. Rio de Janeiro: FGV, 2007.

ELLRAM, L. A toxonomy of total cost of ownership models. Journal of Business Logistics, v. 15, n. 1, 1994.

FARINA, E. Q.; AZEVEDO, P. F.; SAES, M. S. M. Competitividade: mercado, estado e organizações. São Paulo: Singular, 1999. PMCid:PMC1752775.

FÁVERO, L. P. et al. Análise de dados: modelagem multivariada para tomada de decisões. Rio de Janeiro: Elsevier, 2009.
INTERNATIONAL ASSOCIATION FOR CONTRACT AND COMMERCIAL MANAGEMENT - IACCM. Disponível em: <http://www.iaccm.com>. Acesso em: 28 jun. 2010.

LEMPEREUR, A. P.; SEBENIUS, J. Manual de Negociações Complexas. 2. ed. Rio de Janeiro: FGV, 2007.

MONCZKA, R. M.; TRENT, L.; HANDFIELD, R. B. Purchasing and Supply Management. 4th ed. Mason: Cengage Learning, 2005.

NELSON, R. D. How Delphi went lean. Supply Chain Management Review. New York, 2004.

NISHIGUCHI, T. Strategic Industrial Sourcing. New York: Oxford University, 1994.

NORTH, D. C. Custos de Transação, Instituições e Desempenho Econômico. Rio de Janeiro: Instituto Liberal, 1994.

PIRES, S. R. I. Gestão da cadeia de suprimentos (Supply Chain Management): conceitos, estratégias, práticas e casos. São Paulo: Atlas, 2004.

ROCHA, M. M. Integração Vertical e Incerteza. 2002. Tese (Doutorado em Economia)-Universidade de São Paulo, São Paulo, 2002.

SINDICATO NACIONAL DA INDÚSTRIA DE COMPONENTES PARA VEÍCULOS AUTOMOTORES; ASSOCIAÇÃO BRASILEIRA DA INDÚSTRIA DE AUTOPEÇAS. Desempenho do Setor de Autopeças. São Paulo: SINDIPEÇAS/ABIPEÇAS, 2009-2010. Catálogos.

WILliAMSON, O. E.; MASTEN, S. E. The limits of firms: incentive and bureaucratic Features -The economic institutions of capitalism. New York: Free Press, 1985.

ZARTMAN, A. P. Conceber a teoria da negociação como um meio de resolver conflitos econômicos. In: DUZERT, Y. (Org.). Manual de Negociações Complexas. 2. ed. Rio de Janeiro: FGV, 2007. PMid:18088586. 